\title{
Pathological Findings in the Adrenal Glands of 80 Dogs
}

\author{
Elisângela Olegário da Silva',2, Giovana Wingeter Di Santis', \\ Selwyn Arlington Headley' ${ }^{1}$ Ana Paula Frederico Rodrigues Loureiro Bracarense'
}

\begin{abstract}
Background: The adrenal glands development important endocrine functions and can be affected by primary or secondary diseases. These adrenal gland pathologies may induce clinical syndromes resulting from abnormalities in the production and secretion of hormones. Data about pathological changes in dogs are scarce. Therefore, the aim of the present study was to identify and evaluate the histopathological and epidemiological features of adrenal changes in dogs submitted to necropsy examination from 2005 to 2016 in a Veterinary Teaching Hospital, Londrina, Paraná, Brazil.

Material, Methods \& Results: During this period, 80 animals presented alterations of adrenal gland, representing 5.5\% of all necropsied dogs. The pure breed dogs representing $58.6 \%$ and mixed breed $41.4 \% ; 53.4 \%$ were female and $46.6 \%$ were male. The non-neoplastic adrenal lesions were more frequently (57.5\%) compared to the neoplastic changes (42.5\%). Most of the adrenal glands lesions occurred in older dogs (60\%), following by the middle aged (31.25\%) and young dogs $(8.75 \%)$. The main non-neoplastic lesions observed in the adrenal glands were of hyperplastic $(69.5 \%)$ and circulatory $(26 \%)$ origin, among the earlier, $68.8 \%$ were diffuse hyperplasia and $31.2 \%$ nodular hyperplasia. The nodular hyperplasia was classified as micronodular multifocal in $40 \%$ of the glands with nodular hyperplasia, macronodular multifocal in $30 \%$, micronodular diffuse in $20 \%$, and micronodular focal in $10 \%$. The neoplasms observed were adrenocortical adenoma (ACA) in $44.1 \%$, pheochromocytomas in $23.5 \%$ and adrenocortical carcinomas (ACC) in $11.7 \%$ of the dogs with adrenal tumors. Metastasis from other primary tumors were observed in $20.6 \%$.

Discussion: The data in veterinary literature about the frequency of changes in adrenal gland of dogs are scarce and focus features of diagnosis by ultrasound examination. Most of the adrenal changes observed in the present study were incidental findings observed during the necropsy examination and no specific clinical signs were observed. Non-neoplastic adrenal lesions, mainly of hyperplastic origin, were more frequently observed compared to the neoplastic changes. Differing from previous studies, the diffuse hyperplasia was the most common non neoplastic finding in the adrenal glands. Considering the subclassification of nodular hyperplasia, the multifocal micronodular and macronodular multifocal pattern were the most frequent. In veterinary literature, there are no data about frequency of nodular hyperplastic subtypes. However, in humans the subclassification of nodular hyperplasia is associated to development of endocrine disorders. Previous studies reported lower incidence of neoplastic changes in adrenal gland of dogs compared to the present results. The adrenocortical adenoma was the most common primary tumor, followed by the adrenocortical carcinoma, pheochromocytoma and adrenocortical carcinoma. Congestion and hemorrhage were common findings observed in the adrenal gland primary tumors. On the other hand, necrosis and inflammatory infiltrate were observed only in the adrenocortical carcinomas. These histopathological features may be used as tool in the differential diagnosis between well differentiated adrenocortical carcinoma and adenoma. The histopathological examination was fundamental to differential and definitive diagnosis of all canine adrenal gland disorders observed.
\end{abstract}

Keywords: adrenal gland, histopathological findings, dogs.

Descritores: adrenal, achados histopatológicos, cão.

http://dx.doi.org/10.22456/1679-9216.86253 


\section{INTRODUCTION}

The adrenal glands can be affected by diseases associated with circulatory, inflammatory, hyperplastic, and neoplastic (primary or metastatic) processes [21], and may induce clinical syndromes resulting from abnormalities in the production and secretion of hormones [18].

Most dogs with functional adrenocortical alterations present typical clinical signs of excess glucocorticoid, with polyuria and polyphagia as the dominating features. Other signs of Cushing`s syndrome of dogs include abdominal obesity, weight gain, fatigue, muscle atrophy, cutaneous lesions [2], and are similar to those reported in humans [8]. Dogs with functional pheochromocytomas can present cardiomyopathy and systemic hypertension due the norepinephrine secretion [9].

Previous studies have evaluated the clinical, imaging features and therapy of dogs with hyperadrenocorticism due to adrenocortical tumors $[3,13,23,26,29]$, and cardiomyopathies associated with pheochromocytomas [9]. However, data about frequency and incidence of adrenal gland changes in dogs are scarce $[15,25,28]$. The aim of this study was characterize the pathological findings of adrenal changes in dogs submitted to necropsy examination in a Veterinary Teaching Hospital from 2005 to 2015.

\section{MATERIALS AND METHODS}

Local

A retrospective survey of all adrenal glands submitted for histopathological diagnosis from dogs necropsied at the Laboratory of Animal Pathology, Universidade Estadual de Londrina, Brazil from January 2005 to December 2016 was done.

Data

Data relative to breed, age, sex, clinical signs and histopathological diagnoses of all dogs with an adrenal-associated disease were reviewed and tabulated. When necessary, formalin-fixed and paraffin-embedded block were sectioned at sections of $4 \mu \mathrm{m}$ and stained with hematoxylin-eosin (H\&E) for histopathological evaluation. Hyperplastic adrenocortical lesions were classified as: diffuse (diffuse hyperplastic proliferation without nodules formation), micronodular (nodules measuring less than $0.5 \mathrm{~cm}$ in diameter), and macronodular (nodules measuring more than $0.5 \mathrm{~cm}$ in diameter) with focal, multifocal or diffuse localization [8].

\section{RESULTS}

During the evaluated period of 11 years, 80 animals presented alterations to the adrenal gland, representing 5.5\% (80/1454) of all necropsied dogs. The pure breed dogs representing 58.6\% (852/1454) and the mixed breed dogs $41.4 \%(602 / 1454)$. The sexual distribution of the necropsied dogs was $53.4 \%$ female (776/1454) and 46.6\% male (678/1454). Total of 100 adrenal glands were submitted to histopathological evaluation since 20 dogs (25\%) showed bilateral lesions.

The frequency, percentage, age and sex distribution of the non-neoplastic and neoplastic adrenal disorders are presented in Table 1. Non-neoplastic adrenal lesions were more frequently $(57.5 \% ; 46 / 80)$ and the neoplastic changes were observed in $42.5 \%$ (34/80). Most of the adrenal glands lesions occurred in older dogs (11 years or more), representing $60 \%$ (48/80), following by middle aged (6 to 10 years) $31,25 \%(25 / 80)$ and young dogs (until five years) $8.75 \%$ (7/80). Females represented $75 \%$ (60/80) of the dogs with adrenal pathological changes.

Pure breed dogs represented 58.8\% (47/80) of the animals evaluated during the period and mixed breeds $41.2 \%$ (33/80). The most affected breeds were Poodle $18.1 \%$ (6/47), Rottweiler 18.1\% (6/47), German Shepherd $12.1 \%$ (4/47), Boxer 9\% (3/47) and Yorkshire 9\% (3/47). The reported clinical signs were nonspecific (anorexia, weakness, and tachypnea) in most dogs (73/80) with any adrenal disorder. However, clinical signs of hyperadrenocorticism as polydipsia, polyuria, symmetrical alopecia and abdominal distension were observed in 6.2\% (5/80) being associated with ACA (2), diffuse hyperplasia (2) and nodular hyperplasia (1); while only one dog with adrenal atrophy $(1.25 \%, 1 / 80)$ had clinical signs of hypoadrenocorticism. Clinical signs of tachypnea and tachycardia associate do excess of catecholamine production were observed in one dog with pheochromocytoma $(1.25 \%, 1 / 80)$.

The most of the adrenal changes developed in the cortical region (Figure 1). The main non-neoplastic lesions observed in the adrenal glands were of hyperplastic $69.5 \%(32 / 46)$ and circulatory $26 \%$ (12/46) origin, among the earlier, $47.8 \%$ were diffuse hyperplasia (22/46) and $32.6 \%$ nodular hyperplasia $(15 / 46)$. Further, nodular hyperplasia was observed as a micronodular multifocal pattern in $40 \%(5 / 10)$ of the glands, macronodular multifocal in $30 \%(3 / 10)$, micronodular diffuse in $20 \%(2 / 10)$, and micronodular focal in $10 \%(1 / 10)$. The mean age of the dogs with non-neoplastic adrenal lesions was 9.3 years; female (36/46) dogs were over represented. 
Table 1. Frequency of non-neoplastic and neoplastic histological alterations associated with the mean age and sex of 80 dogs.

\begin{tabular}{cccccc}
\hline Diagnosis & Frequency of alterations & $\%$ of the total adrenal lesions & Mean age (years) & \multicolumn{2}{c}{$\begin{array}{c}\text { Sex } \\
\text { M F }\end{array}$} \\
\hline Non-neoplastic & $(\% /$ total non-neoplastic lesions) & & & \\
\hline Atrophy & $1(2.2 \%)$ & $1.2 \%$ & $2(2)$ & 0 & 1 \\
Congestion & $4(8.6 \%)$ & $5 \%$ & $11(7$ to 14$)$ & 2 & 2 \\
Diffuse hyperplasia & $22(47.8 \%)$ & $27.5 \%$ & $9.5(2$ to 19$)$ & 5 & 17 \\
Hemorrhage & $8(17.4 \%)$ & $10 \%$ & $7.5(1$ to 14$)$ & 2 & 6 \\
Lymphocytic infiltrate & $1(2.2 \%)$ & $1.2 \%$ & $6(6)$ & 0 & 1 \\
Nodular hyperplasia & $10(21.8 \%)$ & $12.5 \%$ & $10.6(7$ to 13$)$ & 1 & 9 \\
Total & $46(100 \%)$ & $57.5 \%$ & $9.3(2$ to 19$)$ & 1036 \\
\hline Neoplastic & $(\% /$ total neoplastic lesions) & $11.6(7$ to 15$)$ & 4 & 11 \\
\hline Adrenocortical adenoma & $15(44.1 \%)$ & $18.7 \%$ & $12.6(9$ to 16$)$ & 0 & 4 \\
Adrenocortical carcinoma & $4(11.8 \%)$ & $5 \%$ & $9(8-10)$ & 1 & 6 \\
Metastasis & $7(20.6 \%)$ & $10 \%$ & $9.2(6$ to 11$)$ & 5 & 3 \\
Pheochromocytoma & $8(23.5 \%)$ & $8.8 \%$ & $10.6(6$ to 16$)$ & 10 & 24 \\
Total & $34(100 \%)$ & $42.5 \%$ & &
\end{tabular}

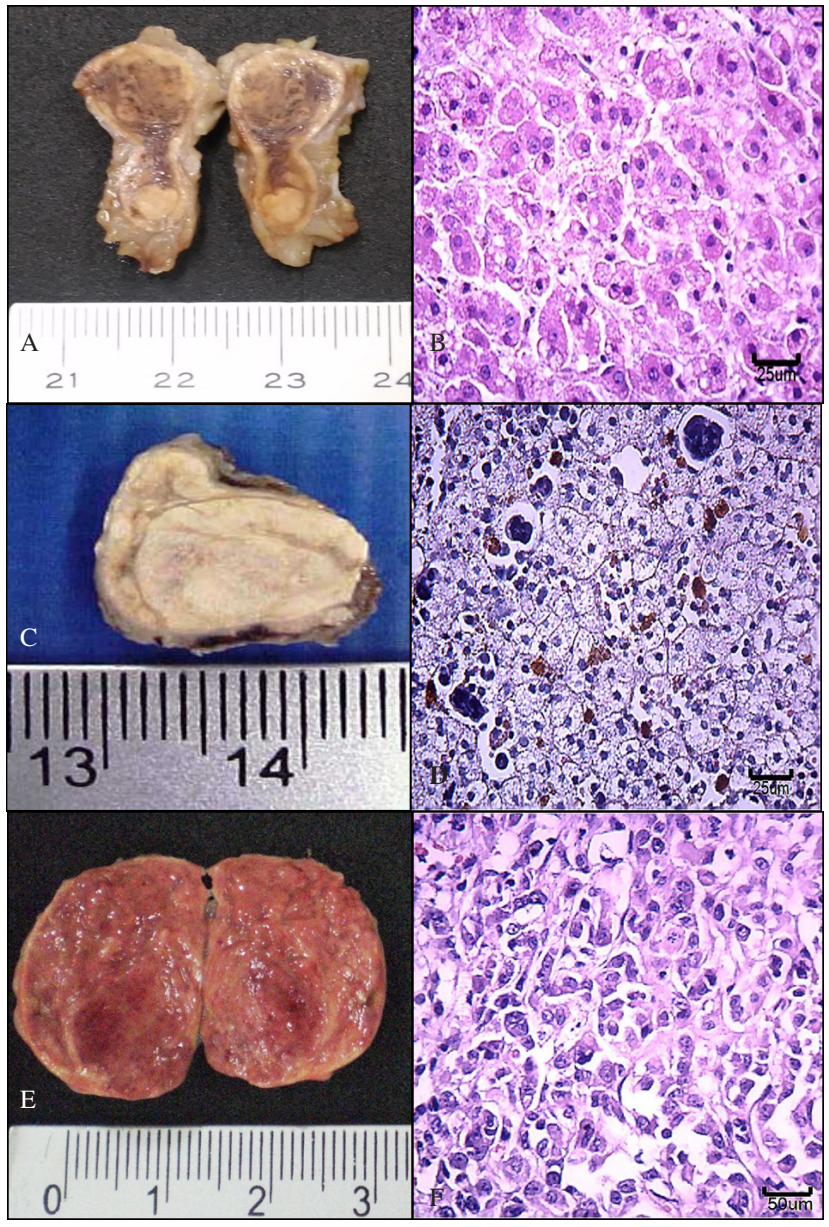

Figure 1. Adrenocortical disorders in dogs. A- Focal micronodular hyperplasianodule well delimitated, yellowish and firm in cortical region (blue arrow). BMicroscopic features of focal micronodular hyperplasia: acidophilic polyhedral cells with occasional cytoplasmic vacuolation resembling the fasciculate layer cells $[\mathrm{H} \& \mathrm{E}, \mathrm{Bar}=25 \mu \mathrm{m}]$. C- Adenoma adrenocortical - nodule well delimitated, expansive, whitish and firm in cortical region (*). D- Microscopic features of adenoma adrenocortical: vacuolated polyhedral cells and presence of megakaryocytes (extramedullary hematopoiesis) (red arrows) [H\&E, Bar $=25 \mu \mathrm{m}]$. E- Carcinoma adrenocortical-neoplastic proliferation poor delimitated, infiltrative, reddish and soft diffuse in adrenal parenchyma. F- Microscopic features of carcinoma adrenocortical: neoplastic cells with high pleomorphism and presence of atypical mitotic figure (red arrow) [H\&E, Bar= $50 \mu \mathrm{m}]$.
The neoplasms observed were ACA in $44.1 \%$ $(15 / 34)$ of the affected glands, pheochromocytomas in $23.5 \%$ (8/34), and adrenocortical carcinomas (ACC) in $11.7 \%(4 / 34)$ of the dogs. The metastases observed in 7 animals (20.5\%) were hemangiosarcoma (2/10), histiocytic sarcoma (1/10), lymphoma (1/10), mammary gland carcinoma $(2 / 10)$ and hepatic carcinoma (1/10). The mean age of the animals with neoplastic lesions were 10.6 years and female (24/34) were more affected as observed in table 1.

The presence of calcification, congestion, hemorrhage, hematopoiesis, inflammatory process and necrosis were evaluated in the cases of diffuse and nodular hyperplasia and neoplastic lesions as observed in Table 2. In the cases of hyperplastic disorders and ACA, the inflammation observed was lymphocytic, since in ACC, metastasis and pheochromocytoma cases, the inflammatory process observed was predominantly neutrophilic.

\section{DISCUSSION}

The adrenal glands have an important role in the endocrine homeostasis and can be affected by several diseases in association or not to systemic alterations [21]. In this study, $5.5 \%$ of the dogs submitted to necropsy showed histological changes in the adrenal glands. The non-neoplastic and neoplastic changes were observed in $3.2 \%$ and $2.3 \%$ of the dog population, respectively. The data in veterinary literature about the frequency of non-neoplastic changes in adrenal gland of dogs are scarce [15] or focus only the incidence of nodular hyperplasia [25]. The frequency of primary neoplastic changes in the adrenal gland was $1.8 \%$ 
(27/1454) in the population evaluated. This frequency observed was upper than $0.17 \%$ to $0.76 \%$ reported in the veterinary literature [25]. Previous studies de- scribed the incidence of adrenal tumors (primary and metastatic) accounting for $1.2 \%$ to $1.5 \%$ of all canine tumors $[4,28]$.

Table 2. Histopathological features observed in hyperplastic and neoplastic lesions in adrenal glands of 80 dogs.

\begin{tabular}{|c|c|c|c|c|c|c|}
\hline Specific adrenal disorder & $\begin{array}{c}\text { Calcification } \\
\%(\mathrm{x} / \mathrm{n})\end{array}$ & $\begin{array}{c}\text { Congestion } \\
\%(\mathrm{x} / \mathrm{n})\end{array}$ & $\begin{array}{c}\text { Inflammation } \\
\%(\mathrm{x} / \mathrm{n})\end{array}$ & $\begin{array}{c}\text { Hematopoiesis } \\
\%(\mathrm{x} / \mathrm{n})\end{array}$ & $\begin{array}{c}\text { Hemorrhage } \\
\%(\mathrm{x} / \mathrm{n})\end{array}$ & $\begin{array}{l}\text { Necrosis } \\
\%(\mathrm{x} / \mathrm{n})\end{array}$ \\
\hline \multicolumn{7}{|l|}{ Non-neoplastic } \\
\hline Diffuse hyperplasia & $0 \%$ & $13.6 \%(3 / 22)$ & $4.5 \%(1 / 22)$ & $0 \%$ & $4.5 \%(1 / 22)$ & $0 \%$ \\
\hline Nodular hyperplasia & $0 \%$ & $20 \%(2 / 10)$ & $20 \%(2 / 10)$ & $0 \%$ & $10 \%(1 / 10)$ & $0 \%$ \\
\hline \multicolumn{7}{|l|}{ Neoplastic } \\
\hline Adrenocortical adenoma & $26.6 \%(4 / 15)$ & $73.3 \%(11 / 15)$ & $13.3 \%(2 / 15)$ & $66.6 \%(10 / 15)$ & $53.3 \%(8 / 15)$ & $6.6 \%(1 / 15)$ \\
\hline Adrenocortical carcinoma & $0 \%$ & $75 \%(3 / 4)$ & $75 \%(3 / 4)$ & $0 \%$ & $75 \%(3 / 4)$ & $100 \%(4 / 4)$ \\
\hline Metastasis & $0 \%$ & $57.1 \%(4 / 7)$ & $28.5 \%(2 / 7)$ & $0 \%$ & $57.1 \%(4 / 7)$ & $14.2 \%(1 / 7)$ \\
\hline Pheochromocytoma & $0 \%$ & $75 \%(6 / 8)$ & $25 \%(2 / 8)$ & $0 \%$ & $25 \%(2 / 8)$ & $12.5 \%(1 / 8)$ \\
\hline
\end{tabular}

$(\mathrm{x} / \mathrm{n}): \mathrm{x}=$ number of adrenal gland with the histopathological change; $\mathrm{n}=$ total number of adrenal glands with the diagnosis.

The higher incidence of adrenal changes observed in middle-aged to old-aged dogs was previously described $[5,15]$ and was similar to observed in our data. In addition, pure breed dogs and females were more affected by adrenal changes and reflected the features of the canine population necropsied during the period. In this study, only $8.7 \%$ (7/80) of the animals presented clinical signs associated to cortical or medullar hormonal overproduction. The clinical signs of Cushing's disease were observed in five dogs $(6.2 \%)$, hypoadrenocorticism in one $(1.2 \%)$ and adrenalin hypersecretion in one animal (1.2\%). No specific clinical sign of adrenal changes was observed in $96.2 \%$ (73/80) of the dogs. Therefore, the most of adrenal glands changes were observed during the necropsy examination. In humans $[10,17]$ and domestic animals [25], the non-functional lesions present in the adrenal observed during image or necropsy examination are called incidentalomas. The lack of endocrine manifestations in some adrenocortical tumors, particularly carcinomas as observed in our four cases of ACC, could be explained by the fact that the malignant process is often accompanied by a deletion in some of the enzymes required for cortisol synthesis [30].

In the present study, non-neoplastic lesions $(57.5 \%)$ were more frequent than neoplastic alterations $(42.5 \%)$ in the 80 dogs. The hyperplastic alterations were the most frequent non-neoplastic changes repre- senting 40\% (32/80) of all adrenal lesions observed. The diffuse hyperplasia was observed in $27.5 \%$ (22/80), nodular hyperplasia in $12.5 \%$ (10/80) and representing $1.5 \%$ and $0.7 \%$ of all dog population submitted to necropsy examination differing from previous reports $[15,25]$ which demonstrated a higher frequency of nodular hyperplasia compared to others adrenal changes. The main histopathological finding associated to diffuse hyperplasia was congestion $(20 \%$ of the cases) and in $20 \%$ of the nodular hyperplasia showed congestion and lymphocytic inflammation. Our data showed no histopathological finding with high frequency in the cases of hyperplastic changes.

Diffuse hyperplasia is characterized by the cortex thickening without nodular formation, while hyperplastic nodules can be classified as micronodular (less than $0.5 \mathrm{~cm}$ in diameter) or macronodular (more than $0.5 \mathrm{~cm}$ in diameter) and can be distributed in a focal, multifocal or diffuse pattern [8]. Histologically, the hyperplastic cells showed polyhedral cells with acidophilic cytoplasm to vacuolated large cells resembling the cells of glomerulosa and fasciculata zona [6]. The hyperplastic nodules were not surrounded by a capsule of fibrous connective tissue. This feature is important to differential diagnosis from ACA [5].

Considering nodular hyperplasia, the multifocal micronodular and macronodular multifocal pattern were 
the most frequent representing $40 \%$ and $30 \%$, respectively. There are no data in the veterinary literature about the frequency of nodular hyperplastic subtypes and association with endocrine disorders. The classification of hyperplasia in humans is an important tool. Some studies showed that macronodular hyperplasia is associated with Cushing's syndrome [11], while micronodular hyperplasia is associated to Carney Complex (multiple neoplasia syndrome) [1]. In addition, diffuse hyperplasia is commonly observed in congenital adrenocortical hyperplasia and pituitary or ectopic adrenocorticotropic hormone (ACTH) hypersecretion [14].

The frequency of neoplastic changes observed in the present study was higher compared to available data in the literature [25], representing $42.5 \%$ of adrenal changes. The ACA was the most common primary tumor observed in dogs with adrenal changes (18.7\%) and affected $1 \%$ of the total population evaluated. Studies showed a frequency of $8 \%$ to $58 \%$ of ACA in dogs with adrenal tumors $[15,25,28]$. In the present study, the ACAs represented $44 \%$ of the adrenal tumors cases. Microscopically, the ACA are characterized by vacuolated large cells with vesicular nuclei and distinct nucleoli disposed in nests and cords arrangements, and scarce mitotic figures. The well differentiated cells suggest an origin from the zona fasciculata $[5,6]$.

The ACC was observed in $11.7 \%$ of the dogs with neoplastic changes affecting $0.27 \%$ of the dog population necropsied in this study. Previous studies showed a frequency of $18 \%$ to $22 \%$ of ACC in dogs with neoplastic changes in the adrenal glands [7,25,28]. In the histopathological evaluation in our study, three cases of ACC presented well-differentiated neoplastic cells and one case showed high cellular pleomorphism and mitotic index, atypical mitosis and binucleation. Despite the mild histopathological malignancy features observed in two ACC, the animals showed focus of metastases in lung, kidney and central nervous system. Invasion of the adrenal capsule and blood vessels by the neoplastic cells are features described in the literature [5] and were present in all cases of ACC. However, invasion of the posterior vena cava wall and the adventitial layer of the abdominal aorta [20,22] were not observed. In humans, the most common sites described of metastasis of ACC were the regional lymph nodes, peritoneal and pleural surfaces, liver, lung and bone [19,30] and were associated to trabecular and diffuse growth pattern of neoplastic cells in the ACC tumor. In our study, the three metastatic cases of ACC showed diffuse and trabecular growth pattern, however, there are no data in the literature associating the histological pattern with a metastatic behavior in animals. Metastases to distant sites are rare and were described in liver, lung, kidney, nervous system and mesenteric lymph nodes of dogs [5,16,22,31,32].

The adrenal glands with ACA showed multifocal areas of extramedullary hematopoiesis $(66.6 \%)$ associated with congestion $(73.3 \%)$ and hemorrhage (53.3\%) and the main histopathological findings found in ACC were necrosis (100\%), congestion (75\%), hemorrhage $(75 \%)$ and inflammatory infiltrate $(75 \%)$. These results showed that necrosis and inflammatory infiltrate were features of ACC and may be used in the differential diagnosis of ACA.

The diagnosis of pheochromocytoma was observed in $23.5 \%$ of the dogs with adrenal neoplasia and the incidence in the analysed population was $0.55 \%$. Previous studies showed a frequency of tumors (neuroendocrine origin) in the medullar region varying from $8 \%$ to $22 \%$ in dogs with adrenal tumors $[15,25,28]$, accounting for $0.01 \%$ to $0.1 \%$ of all canine tumors [12]. However, there are no data focusing on the frequency of pheochromocytoma in dogs. According to the veterinary literature, more than $50 \%$ of these tumours are malignant and invade through the capsule of the adrenal gland into adjacent caudal vena cava $[2,5,21]$. In the present study, this finding was observed in $25 \%$ (2/8) of the dogs.

Metastasis to adrenal glands have been reported in $30 \%$ of human patients and the bilateral involvement is observed in 50\% [8,24,27]. In dogs, the rate of metastasis to the adrenal was reported in $21 \%$ with bilateral involvement in $55 \%$ of the oncologic patients [18]. In our study, we observed that metastasis accounted for $20.6 \%$ of the neoplastic changes in adrenal glands and bilateral involvement occurred in $42.8 \%$. On the other hand, frequency rates of adrenal metastasis varying from 3 to $5 \%$ in dogs with adrenal tumours was also reported $[25,28]$.

\section{CONCLUSIONS}

The results of the present study showed a prevalence of non-neoplastic and non-functional disorders in the adrenal, mainly diffuse and nodular cortical hyperplasia. The most of adrenal changes were necropsy findings and the histopathological evaluation was fundamental to definitive diagnosis of the adrenal disorders.

Declaration of interest. The authors report no conflicts of interest. The authors alone are responsible for the content and writing of paper. 


\section{REFERENCES}

1 Almeida M.Q. \& Stratakis C.A. 2010. Carney complex and other conditions associated with micronodular adrenal hyperplasias. Best Practice \& Research Clinical Endocrinology \& Metabolism. 24(6): 907-914.

2 Bailey D.B. \& Page R.L. 2007. Tumors of the endocrine system, p. 583-609. In: Withrow S.J. \& Vail D.M. (Eds). Withrow \& MacEwen's Small Animal Clinical Oncology. 4th edn. St. Louis: Saunders Elsevier, pp.583-609.

3 Bargellini P., Orlandi R., Dentini A., Paloni C., Rubini G., Fonte P., Diana A., Peterson M.E. \& Boiti C. 2006. Use of contrat-enhanced ultrasound in the differential diagnosis of adrenal tumor in dogs. Journal of American Animal Hospital Association. 52(3): 132-143.

4 Brodey R.S. 1970. Canine and feline neoplasia. Advances in Veterinary Science and Comparative Medicine. 14(1): 309-354.

5 Capen C.C. 2002. Tumors of the adrenal gland. In: Meuten D.J. (Ed). Tumor in Domestic Animals. 4th edn. Ames: Iowa State Press, pp.629-637.

6 Carney J.A. 1997. Adrenal gland. In: Stenberg S.S. (Ed). Histology for Pathologists. 2nd edn. Philadelphia: LippincottRaven Publishers, pp.1107-1131.

7 Cotchin E. 1954. Neoplasia in the dog. Veterinary Records. 66(1): 879-885.

8 DeLellis R.A. \& Mangray S. 2004. The adrenal glands. In: Mills S.E. (Eds). Sternberg's Diagnostic Surgical Pathology. 4th edn. Philadelphia: Lippincott Williams \& Wilkins, pp.338-343.

9 Edmondson E.F., Brighit J.M., Halsey C.H. \& Ehrhart E.J. 2015. Pathological and cardiovascular characterization of pheochromocytoma associated cardiomyopathy in dogs. Veterinary Pathology. 52(2): 338-343.

10 Fassnacht M., Arlt W., Bancos I., Dralle H., Newell-Price J., Sahderv A., Tabarin A., Terzolo M., Tsagarakis S. \& Dekkers O.M. 2016. Management of adrenal incidentalomas: European Society of Endocrinology Clinical Practice Guideline in collaboration with the European Network for the study of adrenal tumors. European Journal of Endocrinology. 175(2): G1-G34.

11 Fragoso M.C.B.V., Wanichi I.Q., Cavalcante I.P. \& Mariani B.M.P. 2016. The role of gsp mutations on the development of adrenocortical tumors and adrenal hyperplasia. Frontiers in Endocrinology. 7(1): 1-7.

12 Gilson S.D., Withrow S.J., Wheeler S.L. \& Twedt D.C. 1994. Pheochromocytoma in 50 dogs. Journal of Veterinary Internal Medicine. 8(3): 228-232.

13 Gregori T., Mantis P., Benigni L., Priestnall S.L. \& Lamb C.R. 2015. Comparison of computed tomographic and pathologic findings in 17 dogs with primary adrenal neoplasia. Veterinary Radiology \& Ultrasound. 56(2): 153-159.

14 Imaki T., Nause M. \& Takamo K. 2004. Adrenocortical hyperplasia associated with ACTH-dependent Cushing's syndrome: comparison of the size of adrenal glands with clinical and endocrinological data. Endocrinology Journal. 51(1): 89-95.

15 Juodziukynienė N., Aniuliene A., Sabeckiene J. \& Valanciute A. 2014. The histopathological evaluation of dogs adrenal glands. Revista de Medicina Veterinaria e Zootecnia. 66(88): 12-19.

16 Keiser M., Fluckiger M., Gardelle O. \& Reusch C. 1999. Mitotane treatment in a dog with a recurring adrenocortical carcinoma- a case report. Schweizer Archiv Fur Tierheilkunde. 141(1): 279-285.

17 Kuruba R. \& Gallagerer S.F. 2008. Current management of adrenal tumors. Current Opinion in Oncology. 20(1): 34-36.

18 Labelle P. \& De Cock H.E.V. 2005. Metastatic tumors to the adrenal glands in domestic animals. Veterinary Pathology. 42(1): 52-58.

19 Lack E.E. 2002. Tumors of the adrenal gland. In: Fletcher C.D.M. (Ed). Diagnostic Histopathology of Tumors. v.2. 2nd edn. Philadelphia: Churchill Livingstone, pp.1057-1082.

20 Lang J.M., Schertel E., Kennedy S., Wilson D., Barnhart M. \& Danielson B. 2011. Elective and emergency surgical management of adrenal gland tumors: 60 cases (1999-2006). Journal of American Animal Hospital Association. 47(6): 428-435.

21 La Perle K.M.D. 2012. Endocrine system. In: Zachary J. \& McGavin M.D. (Eds). Pathologic Basis of Veterinary Disease. 5th edn. St Louis: Elsevier Mosby, pp.660-696.

22 Liste F., Cuevas M., Gascon M., Gascon M., Garcia de Jalon J. \& Cuevas I. 1997. Ultrasonographic diagnosis of adrenocortical caarcinoma in a dog. Veterinary Records. 140(13): 339-341.

23 Loste A., Borobia M., Borobia M., Lacasta D., Carbonell M., Basurco A. \& Marca M.C. 2013. Adrenal gland tumours. Different clinical presentations in three dogs: a case report. Veterinarni Medicina. 58(7): 377-384. 
24 Mor F., Lahav M., Kipper E. \& Wysenbeek A.J. 1985. Addison's disease due to metastases to the adrenal glands. Postgraduate Medical Journal. 61(717): 637-639.

25 Myers N.C. 1997. Adrenal incidentalomas. Veterinary Clinics of North America: Small Animal Practice. 27(2): 381399.

26 Penninck D.G., Feldman E.C. \& Nyland T.G. 1988. Radiological features of canine hyperadrenocorticism caused by autonomously functioning adrenocortical tumor: 23 cases (1978-1986). Journal of American Veterinary Medical Association. 192(1): 1604-1608.

27 Piga A., Bracci R., Porfiri E. \& Cellerino R. 1995. Metastatic tumors of the adrenals. Minerva Endocrinology. 20(1): 79-83.

28 Preister W.A. \& Mckay F.W. 1980. The occurrence of tumors in domestic animals. National Cancer Institute Monographs. 54(1): 1-100.

29 Reusch C.E. \& Feldman E.C. 1991. Canine Hyperadrenocorticism due to adrenocortical neoplasia-pretreatment evaluation of 41 dogs. Journal of Veterinary Internal Medicine. 5(1): 3-10.

30 Rosai J. 2004. Adrenal gland and other paraganglia. In: Rosai J. (Ed). Rosai and Ackerman's Surgical Pathology. v.1. 4th edn. Phialdelphia: Mosby, pp.1115-1162.

31 Silva E.O. \& Bracarense A.P.F.R.L. 2016. Cinical and pathological features of canine metastatic adrenocortical carcinoma. Acta Scientiae Veterinariae. 44(Suppl 1): 143.

32 Van Sluijs F.J., Sjollema B.E., Voorhout G., Van Den Ingh T.S. \& Rijnberk A. 1995. Results of adreneletomy in 36 dogs with hyperadrenocorticism caused by adrenocortical tumors. Veterinary Quaterly. 17(3): 113-116. 